\title{
The Car Cushion Hypothesis: Bigger Cars Lead to More Risk Taking-Evidence from Behavioural Data
}

\author{
B. Claus $^{1}$ (D) $\cdot$ L. Warlop ${ }^{2}$ (D)
}

Received: 27 August 2021 / Accepted: 24 January 2022 / Published online: 5 February 2022

(c) The Author(s), under exclusive licence to Springer Science+Business Media, LLC, part of Springer Nature 2022

\begin{abstract}
Car traffic and accidents involving cars create an enormous societal cost, particularly in terms of negative consequences for public health. Mitigating these effects is a daily concern for public and private institutions and people around the world. At least a subset of accidents is attributable to the amount of risk drivers allow in their driving and in related behaviour like mobile phone use or substance abuse. Our study looks at the effect of car size on risk taking. While literature highlights several behavioural effects of car size, the direction of causality of these effects is not always clear, and empirical evidence is lacking. Two behavioural and consequential studies support that car size affects risk taking in driving and that this increase in risk taking generalizes to other domains as well. Based on these results and in line with literature showing that social stability and security can affect financial risk taking, we propose the "car cushion hypothesis." This hypothesis suggests that bigger cars make people feel more secure, which affects their behaviour in terms of generalized risk taking. We discuss policy implications aimed at contributing to reducing the societal and public health cost of car traffic.
\end{abstract}

Keywords Risk taking · Traffic fatalities · Car traffic $\cdot$ Car size $\cdot$ Cushion hypothesis

According to the World Health Organization (WHO) (2018), 1.35 million people lose their lives in traffic each year. Road accidents are globally the leading cause of death in the 5-29 age group and the eighth leading cause across all ages. On top of casualties, about 50 million people are injured in traffic every year. Next to this human tragedy, the economic loss associated with traffic accidents is estimated at $0.12 \%$ of global GDP (Chen et al., 2019), further contributing to the enormous societal cost of road traffic (French \& Gumus, 2021). Mitigating the human and economic cost of road traffic is a priority for the WHO expressed

B. Claus

b.claus@ieseg.fr

L. Warlop

luk.warlop@bi.no

1 Department of Marketing and Sales Management, IESEG School of Management, 3 rue de la Digue, 59000 Lille, France

2 Department of Marketing, BI Norwegian Business School, Nydalsveien 37, 0484 Oslo, Norway 
in UN Sustainable Development Goal 3.6 to halve the number of global deaths and injuries from road traffic accidents (UN, 2015).

Car traffic is at the centre of this challenge. Not only do car occupants take $34 \%$ of registered road casualties (WHO, 2018), car crashes are also a leading contributor to casualties in other categories, like cyclists and pedestrians (Dozza et al., 2016; NHTSA, 2020; NSC, 2019; Yasin et al., 2020). Accordingly, manufacturers and governments try to mitigate the risks of car driving with a host of safety equipment (Richter et al., 2005) and legislation (French \& Gumus, 2018). Car safety is an important selling argument for many (Winston \& Mannering, 1984; Wu et al., 2014). However, in driving — as in life-experiencing risk can be the corollary of certain desirable states like excitement, stimulation, and exploration and rewards like gaining time. Thus, various literature indicates that people have a preferred, non-zero level of risk and will behave in a way that targets this non-zero level of risk (Adams, 1999; Steenkamp \& Baumgartner, 1992). For example, during the COVID-19-related lockdown, increased speeding partially offset mitigated traffic accidents and mortality from reduced car traveling (NHTSA, 2020; Shilling \& Waetjen, 2020).

Finding drivers of risk taking in driving and related behaviour constitutes important leverage to mitigating the societal and public health cost of car traffic (D'Onofrio et al., 2006). Literature proposes that stable personality factors (Bone \& Mowen, 2006; Lauriola et al., 2014), or early age environment (Wang et al., 2014), partially determine risk preferences. However, literature also mentions situational influences on driving-related risk taking. Car features, for example, influence intentions towards risky behaviour (Horswill \& Coster, 2010). Car size is a particularly important feature. On the one hand, people choose large cars because they see them as safer, thus avoiding risk (Thomas \& Walton, 2008). On the other hand, large cars are much more likely to be involved in accidents (Abay et al., 2013; Evans, 1985; Wasielewski \& Evans, 1985), implying their drivers take more risk.

Here, a question of direction of causality presents itself (see also Horswill \& Coster, 2010): Do people who seek more risk select bigger cars? Alternatively, do bigger cars affect people so that they take more risk? Contributing to answering the second question is the aim of this report. Literature presents some indication that bigger cars positively affect people's intentions to take risk (Horswill \& Coster, 2010), but behavioural evidence is lacking. Cars have been getting bigger over the last decades, and the market share of bigger cars has increased (CarGurus.com, 2020; EPA, 2021). As car choice is typically subject to social norms and bandwagon effects (Berneiser et al., 2021), the trend of increasing car size might proliferate. Bigger cars have more potential for doing damage in traffic (Abay et al., 2013; Wood, 1997). Thus, any effect of car size on driving-related risk taking has important direct consequences on traffic safety. Moreover, risk attitudes can affect risk taking across domains (Beisswingert et al., 2016; Zou \& Scholer, 2016). Car size might therefore affect risk taking in a broad sense-including in ways that feed back into traffic risk, like is the case with substance abuse. Whether car size affects risk taking is therefore of substantial importance in a comprehensive approach to addressing road traffic's societal cost and public health consequences (D'Onofrio et al., 2006; French \& Gumus, 2021). In this report, we provide theoretical and empirical evidence for the "car cushion hypothesis," the notion that bigger cars contribute to taking risk in and outside of driving contexts. Thus, we hope to contribute to bases for interventions addressed at reducing the societal and public health cost of car traffic. 


\section{Theoretical Background}

\section{The Car Cushion Hypothesis and Generalized Risk Taking}

In their seminal work, Hsee and Weber (1999) find that higher levels of social connectivity can provide people with a sense of security that positively affects their risk tolerance in financial decisions - a mechanism they label the "cushion hypothesis." This hypothesis has roots in earlier findings that risk perception-not risk attitude-drives risk taking behaviour (Weber \& Milliman, 1997). Assessments of risk much more affect than cognition-driven (Loewenstein et al., 2001), and risk tolerance is strongly related to feelings of control (Slovic, 1987). Comfort, stability, and safety in the social domain can make one feel supported, making risk in the financial domain look less daunting. Oppositely, losing control in one domain (a game) affects subsequent financial risk taking (Beisswingert et al., 2016), and a focus on controlling loss affects risk taking across domains like health, social settings, ethics, and gambling (Zou \& Scholer, 2016). Receiving physical touch affects financial risk taking (Levav \& Argo, 2010), highlighting the affective nature of risk processing (Loewenstein et al., 2001).

Similar to Hsee and Weber's (1999) general cushion hypothesis, we propose the "car cushion hypothesis": Bigger cars provide people with a sense of security and control (Thomas \& Walton, 2008) that-similar to other instances of safety and control (Slovic, 1987)_will lead to more risk taking (H1). Importantly - and similar to the cushion hypothesis-we propose that the effect of car size on risk taking affects risk taking in a general sense, beyond the specific context of driving cars.

\section{Process Evidence: Safety Perceptions and Regulatory Focus}

We propose and test two kinds of process evidence.

First, the notion that the car cushion hypothesis hinges on a feeling of safety, security, and comfort (Hsee \& Weber, 1999; Thomas \& Walton, 2008) puts perceptions of safety central in the process of how car size affects risk taking. Thus, we propose that this perception of safety mediates the effect of car size on risk taking $(\mathrm{H} 2)$.

Second, we build on Regulatory Focus Theory (Higgins, 1997) to propose that the car cushion hypotheses finds boundary conditions in high promotion and prevention tendencies. High scores on promotion focus reflect an aspiration for accomplishment, associated with risk proneness. High scores on prevention focus reflect seeking safety. Although of course oppositely related, prevention and promotion tendencies operate to some extent independently. Therefore, regulatory focus is measured as two separate subscales of promotion and prevention focus. Literature shows that these tendencies affect risk attitudes in traffic (Craciun et al., 2017). We propose that strong regulatory predispositions-either promotion or prevention-reduce consumers' sensitivity to context effects. Consumers that based on strong promotion tendencies seek risk will do so regardless of context. Similarly, consumers who avoid risk based on strong prevention tendencies will do so regardless of context. It is when regulatory tendencies are less pronounced-i.e., at lower levels of promotion and prevention-that context effects can occur. Thus, we propose that regulatory focus moderates the effect of car size on risk taking (H3). Two experimental studies tested these inferences. 


\section{Methodology and Results}

\section{Study 1: The Effect of Car Size on Driving Behaviour}

In this study, we assess behavioural evidence of a positive effect of car size on risk taking in a driving context. We collaborated with a Belgian non-profit that operates a full-scale, realistic driving simulator developed by Green Dino ${ }^{1}$ for driver training. We manipulated the size of the car that participants believed to be driving. In reality, we set the simulator with identical parameters between conditions. The dependent measure was a composite measure of driving intensity—commonly related to crash risk (Eboli et al., 2017). We measured regulatory focus to assess whether the effect of car size on risk taking only occurs at low levels of promotion and prevention scores (H3). Additionally, we measured mood, driving experience, and attitude towards driving as covariates of our dependent measure driving intensity. Mood can influence evaluations of risk (Forgas, 1995), and we expected driving experience and attitude to make participants more risk tolerant. Considering the limited attainable sample size that results from the operational limitations of working with a car simulator, we collected these covariates to reduce error variance and obtain a more accurate measurement of our hypothesized effects (Meyvis \& Van Osselaer, 2018).

\section{Material and Procedure}

Participants ( $n=49,23$ female, ages 18-23) were undergraduate students from a large European university, part of a university subject pool for behavioural studies. They came individually to a dedicated room at the university for a 20-min session in return for a monetary compensation of $8 €$. Candidates needed a valid driver's license to participate. While the complex experimental procedure and limited availability of only a single driving simulator prevented us from collecting a larger sample of data, a power analysis showed adequate power between $81.5 \%$ and $99.4 \%$ (with $\alpha=0.05$ ) for the analyses below.

First, participants learned about the procedure on a computer screen. They were told that we were studying people's driving behaviour in response to specific circumstances on the road. We assessed participants' driving experience and attitude and measured participants' regulatory focus as two separate scales of promotion and prevention focus. We also assessed participants' mood based on the PANAS (Watson et al., 1988). We then explained that the rest of this study would take place in the driving simulator, and participants were at that point randomly assigned to the car size condition. They were shown a picture of the car they would drive with the model name mentioned, which was either a big car (a Toyota Avensis wagon) or a small car (a Toyota Yaris). Brand was deliberately kept constant and consistent with the layout of the interior of the simulator, which showed the brand logo placed centrally on the steering wheel. The last computer screen then invited participants to take place in the driving simulator. The simulator asked participants to drive naturally throughout the session. Participants were first allowed a two-min practice drive. They were then instructed to drive the car for $10 \mathrm{~min}$ along a predetermined route. An average traffic density was simulated, including other cars, pedestrians, and cyclists. During this second drive, the simulator measured speed in kilometres per hour, acceleration and deceleration both as kilometre per hour squared, and throttle and braking as percentage of full pedal

\footnotetext{
${ }^{1}$ http://www.greendino.nl.
} 
Table 1 Independent samples $t$ tests for driving parameters between conditions

\begin{tabular}{lllll}
\hline & $\begin{array}{l}\text { Small car } \\
(n=22)\end{array}$ & $\begin{array}{l}\text { Big car } \\
(n=27)\end{array}$ & $t(47)$ & $p$ value \\
\hline $\begin{array}{lllll}\text { Speed } \\
M\end{array}$ & 8.26 & 8.35 & 0.42 & 0.68 \\
$\quad S D$ & 0.80 & 0.69 & & \\
$\begin{array}{l}\text { Deceleration } \\
M\end{array}$ & 1.79 & 2.31 & 2.99 & 0.004 \\
$\quad S D$ & 0.58 & 0.62 & & \\
Acceleration & & & & \\
$M$ & 1.88 & 2.30 & 2.74 & 0.009 \\
$S D$ & 0.49 & 0.58 & & \\
Throttle & & & & \\
$M$ & 0.25 & 0.31 & 2.24 & 0.030 \\
$S D$ & 0.10 & 0.11 & & \\
Braking & & & & \\
$M$ & 0.16 & 0.20 & 1.07 & 0.29 \\
$S D$ & 0.15 & 0.13 & & \\
\hline
\end{tabular}

articulation, all sampled at five measurements per second. After each ride, the simulation software provided averages of these measures that constitute our dependent variables.

\section{Results and Discussion}

Because some of the driving parameters (e.g., speed, in $\mathrm{km} / \mathrm{h}$ ) were a magnitude bigger than others (e.g., braking, in percentage of maximum braking pedal articulation), we standardized all items before averaging them into a single measure of driving intensity (Cronbach's $\alpha=0.90$ ). Neither mood, driving experiences, nor attitude led to any significant effects. Hence, we did not include these variables for further analysis.

A first analysis revealed that the bigger car led to a higher driving intensity $(M=0.23$, $S E=0.16)$ than the smaller car $(M=-0.28, S E=0.16 ; t(47)=2.26, p=0.023)$. We found significant differences for most individual variables included in driving intensity, except average speed and braking, which show directional effects (Table 1).

The two subscales of regulatory focus-prevention and promotion-did correlate with each other, but only weakly ( $r=-0.31, p=0.028)$, and testing internal consistency with reversed prevention items did not warrant aggregating all items into a single score (Cronbach's $\alpha=0.37$ ), so we used the subscales separately for the remainder of the analysis. A general linear model analysis of the data yielded no three-way interaction between car type, prevention, and promotion $(F<1, n s$.). Analysing the effects of promotion and prevention separately, we did find two significant two-way interactions that qualified the main effect of car type on driving intensity.

First, we found a significant interaction between car type and promotion focus on driving intensity $(F(1,45)=4.36, p=0.042)$. Only participants low in promotion focus were sensitive to the effect of car type. To examine this interaction in more detail, we conducted a spotlight analysis (Fitzsimons, 2008; Irwin \& McClelland, 2001). At one standard deviation above the mean of promotion, we found no significant difference in driving intensity between participants in the small car and those in the big car 


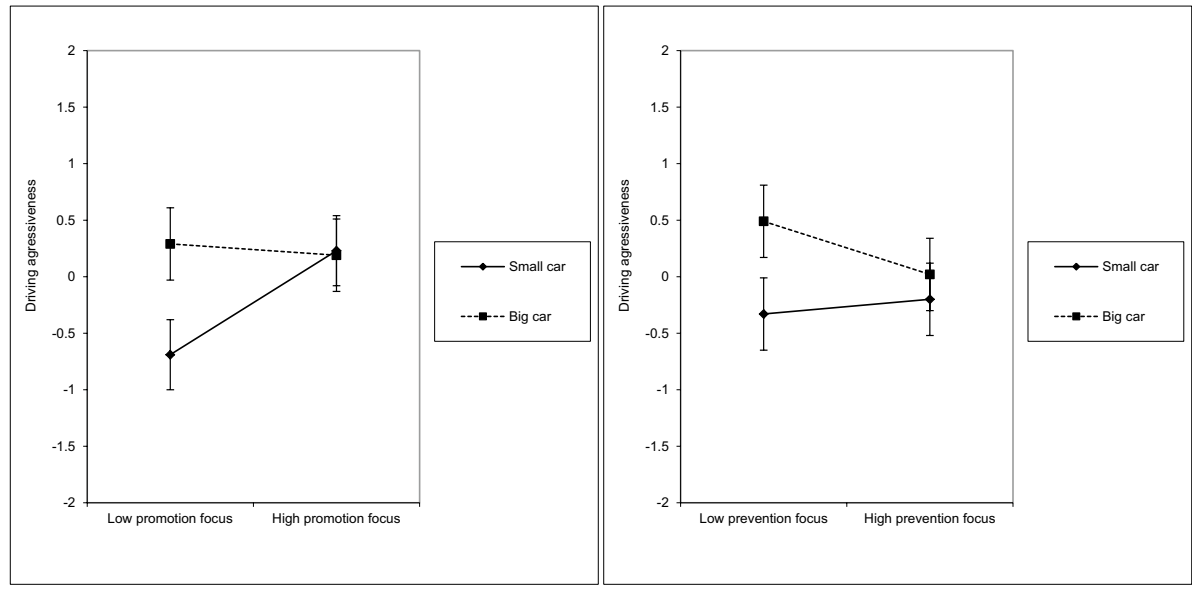

Fig. 1 Driving intensity in a small versus big car, moderated by promotion focus and prevention focus

$\left(M_{\text {small }}=0.23\right.$ and $\left.M_{\text {big }}=0.19 ; \beta=-0.05, S E=0.32, t(45)=-0.14, p=0.89\right)$. At one standard deviation below the mean of promotion, however, participants in the big car seemed to drive more intensively $\left(M_{\text {small }}=-0.69\right.$ and $M_{\text {big }}=0.29 ; \beta=0.99, S E=0.31$, $t(45)=3.20, p=0.0025)$. Participants high in promotion focus drive with high intensity, no matter what car type.

Mirroring the previous result, we found a near significant interaction effect between car type and prevention focus $(F(1,45)=3.09, p=0.086)$. Again, we used spotlight analysis to find that at one standard deviation above the mean of prevention, no significant difference appeared in driving behaviour between participants in the small car and those in the big car $\left(M_{\text {small }}=-0.20\right.$ and $M_{\text {big }}=0.02 ; \beta=0.23, S E=0.32, t(45)=0.70$, $p=0.49$ ). At one standard deviation below the mean of prevention, however, participants in the big car seemed to drive more intensively $\left(M_{\text {small }}=-0.33\right.$ and $M_{\text {big }}=0.49$; $\beta=0.83, S E=0.32, t(45)=2.55, p=0.014)$. Only participants that scored low on prevention focus seemed to be affected by car type. Participants with high prevention focus drove cautiously, no matter what car they believed to be driving (Fig. 1).

When participants believe to be driving a bigger car, this leads to more intense and risky driving behaviour. These results provide initial support for the car cushion hypothesis. Moreover, our results support that promotion and prevention focus can impose boundary conditions on this hypothesis, in that consumers scoring high on either promotion or prevention focus are less susceptible to the context effect on which the car cushion hypothesis hinges.

\section{Study 2: The Effect of Car Size on Generalized Risk Taking}

Study 2 aimed at replicating and extending the effect of car size on risk taking beyond driving. Thus, we seek to find support for the notion that bigger cars encourage generalized risk taking. We set up this second study as a scenario study with behavioural and consequential outcomes, facilitating a bigger sample size to ensure robustness of findings. 


\section{Material and Procedure}

Participants ( $n=214,126$ female, ages 18-27) were subject pool members of the behavioural lab of a large European university who came to our behavioural lab in groups of eight and participated in return for a monetary base payment of $6 €$. Candidates needed a valid driver's license to participate. Our manipulation comprised having participants evaluate one of two car ads, randomly assigned between participants. We asked participants to imagine they were in the market for a new car, and asked to imagine considering the presented car as a candidate choice (Peck et al., 2013). Both cars were from the same brand to control for brand-related associations. The big car condition showed a Mercedes R-class belonging to the MPV category, while the small car condition showed a Mercedes A-class belonging to the compact category. Despite their substantial difference in size, these cars have several design elements in common. We selected four images ${ }^{2}$ for each car, of which three smaller ones from the press kit showing the car from a front-side angle, from the back, and from the side. For each condition, we added one larger image showing the car from a front-side angle, driving, with visible people inside for size reference. As part of the manipulation, we gave a short description of each car, including for the R-class that it was the "largest in its class for all your transportation needs," and for the A-class that it was "small and nimble for navigating the city." We then asked participants to report their perception of the car on four items (Safety, Build quality, Price, Performance), each rated on 7-point Likert-type scales. After rating the car, we told participants this part of the session was completed and asked them to move to the next—ostensibly unrelated-task comprising our dependent measure.

As a dependent measure, we used the Balloon Analog Risk Task (BART; Lejuez et al., 2002). Among attitudinal and behavioural measures of risk taking, the BART has demonstrated itself to have high predictive validity for risk taking in natural settings, including drug use, unprotected sex, gambling, and stealing (Fox \& Tannenbaum, 2011; Lauriola et al., 2014; Lejuez et al., 2002). In the BART, participants receive 5 cents for every time they push the button that pumps a balloon further but lose all of their money on a specific balloon if it pops. Thus, every additional pump increases the total gain but also increases the risk of loss on a trial. Participants can cash out on a balloon if they do not want to take extra risk or give an extra pump to increase their outcome with the risk of popping the balloon. Participants repeated this task over 20 independent balloons. We ensured incentive compatibility by randomly drawing one participant per session who won the money made in the task.

\section{Results and Discussion}

Following instructions on interpreting the BART, we calculated the corrected average number of pumps for each participant, which is the average number of pumps across balloons, excluding balloons that popped (Lejuez et al., 2002). Car size affected the corrected average number of pumps $\left(M_{\text {small }}=14.83\right.$ and $\left.M_{\text {big }}=16.16, t(212)=3.52, p<0.001\right)$. Perceptions of the cars differed significantly with the bigger car scoring higher on all dimensions (see Table 2). To account for potential response bias, we regressed the corrected average number of pumps on condition and the four perception dimensions. Only condition

\footnotetext{
${ }^{2}$ Images were selected from http://media.daimler.com/.
} 


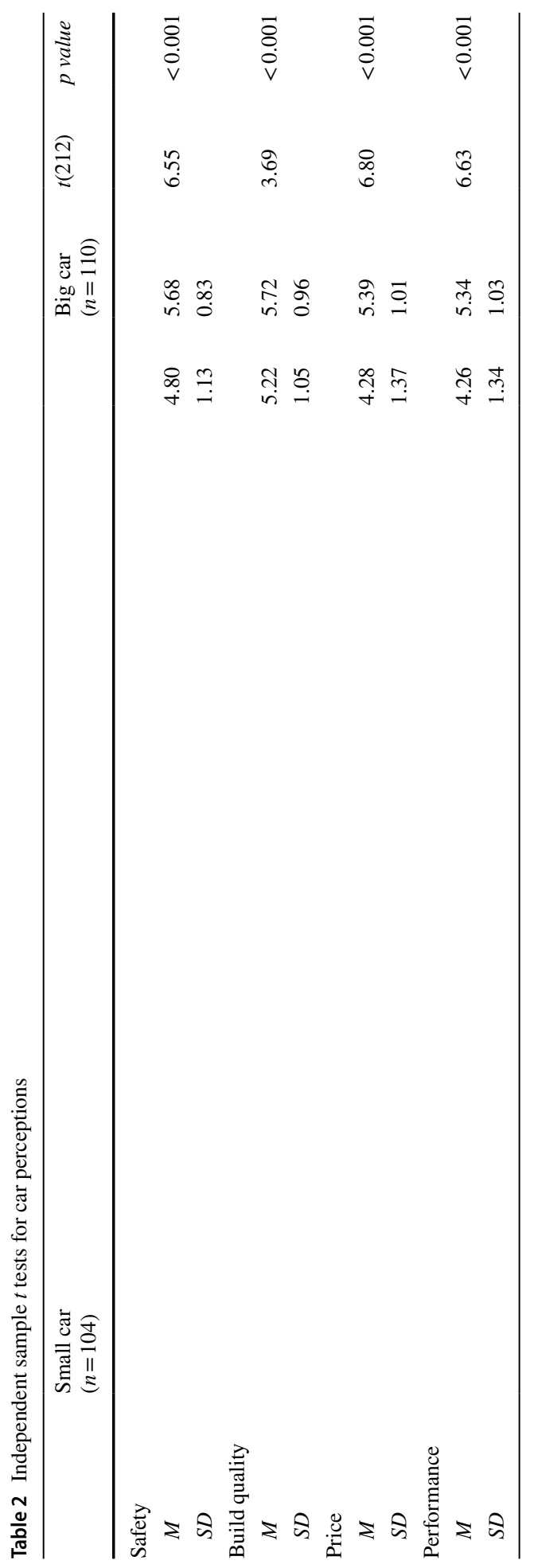


$(\beta=0.17, t(208)=2.19, p=0.029)$ and perceived safety $(\beta=0.18, t(208)=2.16, p=0.032)$ remained significant when including all these predictors.

We tested whether perceived safety mediated the effect of car size on risk taking. A bootstrapping algorithm (PROCESS model 4; Hayes, 2017) supported partial mediation, with a significant indirect effect $(M=0.41, S E=0.18,95 \% \mathrm{CI}[0.055,77])$ and significant direct effect $(M=0.93, S E=0.41,95 \%$ CI $[0.12,1.74])$. We found no support for a similar mediating role of other dimensions. These results highlight the "cushion" aspect of our theorizing, in that perceived car safety stands out as best predicting generalized risk taking.

\section{General Discussion}

Traffic in general and car traffic in particular place a heavy burden on public health (WHO, 2018). Car traffic is multifaceted, including technical, infrastructural, societal, and psychological aspects, with the consumer central in this context. Addressing the societal and public health cost of car traffic requires that measures not just prove their individual effectiveness but are also evaluated for their interactive effects with other parameters of traffic situations, especially regarding secondary effects on consumer behaviour. The latter fully applies to car size. From a technical perspective, bigger cars are preferable because they protect their occupants better (Evans, 1985). However, they get into accidents more frequently (Evans, 1985; Wasielewski \& Evans, 1985) and are a threat to all other road users (Abay et al., 2013; Wood, 1997) and thus one consumer's choice affects other consumers' welfare. The car cushion hypothesis we propose in this report contributes to this puzzle by showing that larger car size increases driving (study 1)- and non-driving (study 2)-related risk taking. Thus, we find that a behavioural effect (of large size on risk taking) exacerbates a technical factor (of large size on damage to others) for large cars' contribution to traffic's societal and public health burden.

Building on literature relating regulatory focus to traffic-related risk attitudes (Craciun et al., 2017), our results also specify boundary conditions for this effect, in that the effect is mitigated for consumers strongly occupied by regulatory promotion or prevention tendencies. Importantly, the results of study 2 suggest the potential for broad behavioural effects and corroborate effects of safety cues on generalized risk taking reported in literature earlier. A notable example is how bike helmet wear affects generalized risk taking and sensation seeking (Gamble \& Walker, 2016). Policy makers might want to look into the relationship between car size and risky choices that interact with driving, like texting (French $\&$ Gumus, 2018) or substance abuse (Elder et al., 2004; Santaella-Tenorio et al., 2020). Moreover, behavioural effects might also spill over to contexts outside of the one containing the safety cue. As an example of the latter, literature reports that drivers of heavy goods vehicles often get into accidents shortly after leaving their vehicle and suggests that this is due to excessive risk taking caused by remaining safety feelings carried over from inside of the heavy vehicle (Fontaine \& Gourlet, 1997).

From a theoretical perspective, we contribute to the understanding of risk taking, extending the cushion hypothesis (Hsee \& Weber, 1999) to driving behaviour. We provide process evidence showing moderation of the effect by regulatory focus, and mediation by perceptions of safety. Moreover, we contribute to a holistic theoretical lens on traffic safety, where we look at the interactive effect of technical traffic parameters and human behaviour. Additionally, our findings contribute to the question about the direction of causality of the 
relationship between car size on the one hand and risk taking and accident proneness on the other hand (Horswill \& Coster, 2010).

From a substantial perspective, we aim for our results to inspire and give direction to public policy makers wishing to investigate, design and implement measures aimed at reducing the societal and public health cost of traffic.

Our findings indicate that incentivizing against larger cars might have the double benefit of reducing incidents (based on a behavioural effect) as well as their severity (based on reduced damage done by smaller cars). Several countries around the world use car size as a partial tax base (India, Lithuania, Malta, Moldova), while others give exemptions to smaller cars (South-Korea) (ACEA, 2020; PwC, 2020). This makes sense, since larger cars proportionally also lay larger claims on public infrastructure (Scheiner et al., 2020). The Netherlands taxes passenger cars based on their mass, and literature shows this allows for full internalization of external costs of car mass (Van Ommeren et al., 2013). Based on our findings, we argue for a broader adoption of car size-related tax bases in order to reduce the societal and public health impact of car traveling and absorb more of its external costs.

In the future, autonomous vehicles (AV) might solve the driving behaviour-related part of our findings. Nonetheless, our finding that risk taking generalizes across contexts might mean the effect of bigger cars migrates to activities like extreme sports, gambling, substance abuse, or other potentially harmful behaviours. As we use a proxy of generalized risk taking rather than measure downstream risky behaviours directly, our results should not be seen as conclusive. We hope they highlight the importance of a holistic view on risk taking in traffic contexts and more particularly inspire future research into the relationship between car size and a broad range of specific risk-taking instances to come to strongly supported and effective public policy measures in the interest of traffic safety.

Acknowledgements The authors would like to thank the editorial team and two reviewers for their helpful guidance in improving this manuscript.

Funding Financial support for data collection was provided by the Belgian Ministry of Science BELSPO Grant FSB-CBSM SD/TA/11.

Data Availability Data available upon request.

\section{Declarations}

Conflict of interest The authors declare no competing interests.

\section{References}

Abay, K. A., Paleti, R., \& Bhat, C. R. (2013). The joint analysis of injury severity of drivers in two-vehicle crashes accommodating seat belt use endogeneity. Transportation Research Part b: Methodological, $50,74-89$.

ACEA. (2020). Co2-Based Motor Vehicle Taxes in the European Union. https://www.acea.auto/fact/overv iew-co2-based-motor-vehicle-taxes-in-the-european-union/. Accessed 3 Feb 2022.

Adams, J. (1999). Cars, cholera, and cows: The management of risk and uncertainty. Policy Analysis, 355, $1-49$.

Beisswingert, B. M., Zhang, K., Goetz, T., \& Fischbacher, U. (2016). Spillover effects of loss of control on risky decision-making. PLOS ONE, 11(3), e0150470. 
Berneiser, J., Senkpiel, C., Steingrube, A., \& Gölz, S. (2021). The role of norms and collective efficacy for the importance of techno-economic vehicle attributes in Germany. Journal of Consumer Behaviour., 20, 1113-1128.

Bone, S. A., \& Mowen, J. C. (2006). Identifying the traits of aggressive and distracted drivers: A hierarchical trait model approach. Journal of Consumer Behaviour: An International Research Review, 5(5), 454-464.

CarGurus.com. (2020). Car size comparison: 1970 vs. 2020 vehicles. https://www.thisismoney.co.uk/ money/cars/article-8986069/Parking-space-sizes-havent-increased-1970s-todays-cars-55-bigger. html. Accessed 20 July 2021.

Chen, S., Kuhn, M., Prettner, K., \& Bloom, D. E. (2019). The global macroeconomic burden of road injuries: Estimates and projections for 166 countries. The Lancet Planetary Health, 3(9), e390-e398.

Craciun, G., Shin, D., \& Zhang, J. Q. (2017). Safe driving communication: A regulatory focus perspective. Journal of Consumer Behaviour, 16(6), e50-e60.

D'Onofrio, G., Becker, B., \& Woolard, R. H. (2006). The impact of alcohol, tobacco, and other drug use and abuse in the emergency department. Emergency Medicine Clinics, 24(4), 925-967.

Dozza, M., Schindler, R., Bianchi-Piccinini, G., \& Karlsson, J. (2016). How do drivers overtake cyclists? Accident Analysis \& Prevention, 88, 29-36.

Eboli, L., Mazzulla, G., \& Pungillo, G. (2017). How to define the accident risk level of car drivers by combining objective and subjective measures of driving style. Transportation Research Partf: Traffic Psychology and Behaviour, 49, 29-38.

Elder, R. W., Shults, R. A., Sleet, D. A., Nichols, J. L., Thompson, R. S., \& Rajab, W. (2004). Effectiveness of mass media campaigns for reducing drinking and driving and alcohol-involved crashes: A systematic review. American Journal of Preventive Medicine, 27(1), 57-65.

EPA. (2021). The 2020 automotive trends report. (EPA-420-R-21-003). https://www.epa.gov/autom otive-trends. Accessed 3 Feb 2022.

Evans, L. (1985). Driver behavior revealed in relations involving car mass. Human behavior and traffic safety (pp. 337-358). Springer.

Fitzsimons, G. J. (2008). Editorial: A death to dichotomizing. Journal of Consumer Research, 35(1), $5-8$.

Fontaine, H., \& Gourlet, Y. (1997). Fatal pedestrian accidents in france: A typological analysis. Accident Analysis \& Prevention, 29(3), 303-312.

Forgas, J. P. (1995). Mood and judgment: The affect infusion model (AIM). Psychological Bulletin, $117(1), 39$.

Fox, C., \& Tannenbaum, D. (2011). The elusive search for stable risk preferences. Frontiers in Psychology, 2, 298.

French, M. T., \& Gumus, G. (2018). Watch for motorcycles! The effects of texting and handheld bans on motorcyclist fatalities. Social Science \& Medicine, 216, 81-87.

French, M. T., \& Gumus, G. (2021). Death on the job: The Great Recession and work-related traffic fatalities. Social Science \& Medicine, 280, 113979.

Gamble, T., \& Walker, I. (2016). Wearing a bicycle helmet can increase risk taking and sensation seeking in adults. Psychological Science, 27(2), 289-294.

Hayes, A. F. (2017). Introduction to mediation, moderation, and conditional process analysis: A regression-based approach. Guilford Publications.

Higgins, E. T. (1997). Beyond pleasure and pain. American Psychologist, 52(12), 1280-1300.

Horswill, M. S., \& Coster, M. E. (2010). The effect of vehicle characteristics on drivers' risk-taking behaviour. Ergonomics, 45(2), 85-104.

Hsee, C., \& Weber, E. (1999). Cross-national differences in risk preference and lay predictions. Journal of Behavioral Decision Making, 12, 165-179.

Irwin, J. R., \& McClelland, G. H. (2001). Misleading heuristics and moderated multiple regression models. Journal of Marketing Research, 38(1), 100-109.

Lauriola, M., Panno, A., Levin, I. P., \& Lejuez, C. W. (2014). Individual differences in risky decision making: A meta-analysis of sensation seeking and impulsivity with the balloon analogue risk task. Journal of Behavioral Decision Making, 27(1), 20-36.

Lejuez, C. W., Read, J. P., Kahler, C. W., Richards, J. B., Ramsey, S. E., Stuart, G. L., Strong, D. R., Brown, R. A. (2002). Evaluation of a behavioral measure of risk taking: The Balloon Analogue Risk Task (BART). Journal of Experimental Psychology: Applied, 8(2), 75-84.

Levav, J., \& Argo, J. J. (2010). Physical contact and financial risk taking. Psychological Science, 21(6), 804-810. 
Loewenstein, G. F., Weber, E. U., Hsee, C. K., \& Welch, N. (2001). Risk as feelings. Psychological Bulletin, 127(2), 267.

Meyvis, T., \& Van Osselaer, S. M. J. (2018). Increasing the power of your study by increasing the effect size. Journal of Consumer Research, 44(5), 1157-1173.

NHTSA. (2020). Early estimates of motor vehicle traffic fatalities and fatality rate by sub-categories through June 2020. (DOT HS 813 054). https://crashstats.nhtsa.dot.gov/Api/Public/Publication/ 813054. Accessed 3 Feb 2022.

NSC. (2019). Bicycle deaths. https://injuryfacts.nsc.org/home-and-community/safety-topics/bicycle-deaths/. Accessed 16 July 2021.

Peck, J., Barger, V. A., \& Webb, A. (2013). In search of a surrogate for touch: The effect of haptic imagery on perceived ownership. Journal of Consumer Psychology, 23(2), 189-196.

PwC. (2020). 2020 PwC Global Automotive Tax Guide (P. G. A. T. Network, Trans.). PricewaterhouseCoopers.

Richter, M., Pape, H.-C., Otte, D., \& Krettek, C. (2005). Improvements in passive car safety led to decreased injury severity-a comparison between the 1970s and 1990s. Injury, 36(4), 484-488.

Santaella-Tenorio, J., Wheeler-Martin, K., DiMaggio, C. J., Castillo-Carniglia, A., Keyes, K. M., Hasin, D., \& Cerdá, M. (2020). Association of recreational cannabis laws in Colorado and Washington state with changes in traffic fatalities, 2005-2017. JAMA Internal Medicine, 180(8), 1061-1068.

Scheiner, J., Faust, N., Helmer, J., Straub, M., \& Holz-Rau, C. (2020). What's that garage for? Private parking and on-street parking in a high-density urban residential neighbourhood. Journal of Transport Geography, 85, 102714.

Shilling, F., \& Waetjen, D. (2020). Special Report (Update): Impact of COVID19 mitigation on numbers and costs of California traffic crashes. Transportation Research Board Weekly, 1-11. https://trid.trb. org/view/1701950.

Slovic, P. (1987). Perception of risk. Science, 236(4799), 280-285.

Steenkamp, J.-B.E.M., \& Baumgartner, H. (1992). The role of optimum stimulation level in exploratory consumer behavior. Journal of Consumer Research, 19(3), 434-448.

Thomas, J. A., \& Walton, D. (2008). Vehicle size and driver perceptions of safety. International Journal of Sustainable Transportation, 2(4), 260-273.

UN. (2015). Transforming our world: The 2030 agenda for sustainable development. United Nations.

Van Ommeren, J., Rietveld, P., Zagha Hop, J., \& Sabir, M. (2013). Killing kilos in car accidents: Are external costs of car weight internalised? Economics of Transportation, 2(2), 86-93.

Wang, B., Deveaux, L., Li, X., Marshall, S., Chen, X., \& Stanton, B. (2014). The impact of youth, family, peer and neighborhood risk factors on developmental trajectories of risk involvement from early through middle adolescence. Social Science \& Medicine, 106, 43-52.

Wasielewski, P., \& Evans, L. (1985). Do drivers of small cars take less risk in everyday driving? Risk Analysis, 5(1), 25-32.

Watson, D., Clark, L. A., \& Tellegen, A. (1988). Development and validation of brief measures of positive and negative affect: The PANAS scales. Journal of Personality \& Social Psychology, 54(6), 1063-1070.

Weber, E. U., \& Milliman, R. A. (1997). Perceived risk attitudes: Relating risk perception to risky choice. Management Science, 43(2), 123-144.

WHO. (2018). Global status report on road safety 2018. World Health Organization.

Winston, C., \& Mannering, F. (1984). Consumer demand for automobile safety. The American Economic Review, 74(2), 316-319.

Wood, D. P. (1997). Safety and the car size effect: A fundamental explanation. Accident Analysis \& Prevention, 29(2), 139-151.

Wu, W. Y., Liao, Y. K., \& Chatwuthikrai, A. (2014). Applying conjoint analysis to evaluate consumer preferences toward subcompact cars. Expert Systems with Applications, 41(6), 2782-2792.

Yasin, Y. J., Grivna, M., \& Abu-Zidan, F. M. (2020). Reduction of pedestrian death rates: A missed global target. World Journal of Emergency Surgery, 15(1), 35.

Zou, X., \& Scholer, A. A. (2016). Motivational affordance and risk-taking across decision domains. Personality and Social Psychology Bulletin, 42(3), 275-289.

Publisher's Note Springer Nature remains neutral with regard to jurisdictional claims in published maps and institutional affiliations. 